\title{
Estimation and performance evaluation of optimal hedge ratios in the carbon market of the European Union Emissions Trading Scheme
}

\author{
John Hua Fan ${ }^{1}$, Eduardo Roca and Alexandr Akimov \\ Department of Accounting, Finance and Economics, \\ Griffith University, Australia
}

\begin{abstract}
Following the introduction of the European Union Emissions Trading Scheme, $\mathrm{CO} 2$ emissions have become a tradable commodity. As a regulated party, emitters are forced to take into account the additional carbon emissions costs in their production costs structure. Given the high volatility of carbon price, the importance of price risk management becomes unquestioned. This study is the first attempt to calculate hedge ratios and to investigate their hedging effectiveness in the EU-ETS carbon market by applying conventional and recently developed models of estimation. These hedge ratios are then compared with those derived for other markets. In spite of the uniqueness and novelty of the carbon market, the results of the study are consistent with those found in other markets - that the hedge ratio is in the range of 0.5 to 1.0 and still best estimated by simple regression models.
\end{abstract}

Key words: hedging, conditional hedge ratio; carbon market; CO2; emissions trading; risk management

\footnotetext{
${ }^{1}$ Corresponding author, Department of Accounting, Finance and Economics, Griffith University, Nathan, Queensland 4111, Australia. Tel. +61 (07) 37357583 Facsimile (07) 37353719
} 


\section{Introduction}

Following the introduction of the European Union Emissions Trading Scheme (EU-ETS) in early 2005, emissions trading has officially become a reality. The EU-ETS is a legally enforceable market-based mechanism, designed for the reduction of greenhouse gas emissions (particularly carbon emissions). By making the price of carbon allowance increasingly expensive, the scheme in the long term, forces emitters to invest into alternative energy technologies whereby achieve a gradual transition from a pollution-intensive industry to a cleaner and sustainable industry.

There are several market participants in the carbon market, the major ones being emitters, financial institutions, investors, market exchanges and the EU commission. Each participant plays a different role, where the EU commission is the regulator/policy maker and emitters are the regulated parties. Trading is not limited to the emitters; investors (usually large corporation or financial institutions) are also permitted to take part. The market exchanges and financial institutions are there to facilitate the operation of the market. Accordingly, the impact on the introduction of emissions trading is expected to vary among these parties. The short and long term uncertainty for each party arising from ETS also differs.

From the policy makers' perspective, the risk they need to manage is to ensure compliance of the proposed trading scheme with the target set in the Kyoto Protocol. From an investor's point of view, the uncertainty will be their portfolio risk 
and return after incorporating the carbon allowances.

Undoubtedly, the emitters, as the regulated, are more affected than other market participants. Due the inescapable nature of compliance, emitters are forced to take into account the carbon allowance cost in their production cost structure. Nevertheless, similar to many other tradable commodities, prices of carbon allowances fluctuate continuously, exhibiting excessive volatility. There is short and long run emphasis on risk management. In the short run, wise decisions towards risk management seem to be based on hedging since no substitutes are available. Over the long run, the significance of hedging remains in order to provide more certainty to alternative energy investing. Besides, the transition from conventional means of power generation to any future substitutions are not expected to be immediate and in fact will take considerably longer to achieve. The speed of transition can be accelerated if more inputs and resources are devoted to it; however the wise current practice or focus should be on the hedging of the price risk of carbon credits (referred to as European Union Allowance, hereafter EUA).

Successful implementation of hedging strategy would provide firms with more certainties (i.e. stability) over their financial capital in short-term. Therefore in long-term, they will have the ability to invest more confidently into alternative energy and other sustainability associated clean technologies.

This paper aims to calculate the optimal hedge ratio in the EU-ETS carbon market 
using conventional and recently developed models of estimation. Based on variance reduction and utility improvement capabilities, the effectiveness of each estimated hedge ratio is going to be evaluated. The novelty of the paper rests in two areas: firstly, this is an original estimation of minimum variance hedge ratio as applied in the EU-ETS carbon market; secondly, this is the first study to compare carbon market hedge ratios with other markets.

The EU-ETS carbon market is one that is new and unique. The underlying commodity in this market - carbon, is one that is very different from those in the other financial markets (e.g. price fundamentals, nature and level of regulation), and one that is still not well understood. EUAs do not pay any interest or dividend, and the only potential cash flow from investing in carbon would be resale price, which is in turn determined by expected market scarcity of carbon allowances (Benz \& Truck, 2009). Like any other marketable asset's price, price of EUA is determined by fundamental demand and supply. However, price determinants for carbon are unique. On demand side, it might be fuel prices, weather and economic growth, whereas on supply side it is determined by the regulators, which is distinctive feature of the market (Seifert, Uhrig-Homburg and Wagner, 2008).

Commentators, such as Alberola, Chevallie and Cheze (2008), Rickels, Duscha, Keller and Peterson (2007), Bonacina and Cozialpi (2009), Hintermann (2009), Mansanet-Bataller, Pardo and Valor (2007) confirmed the link between energy 
prices and EUA prices.

Hence, one might expect that the existing finance theories, concepts and tools may not be applicable in this market. This is the main motivation behind the paper. The optimal hedge ratio as an integral part of risk management has been estimated in other financial markets: Currency (Kroner and Sultan, 1993), Stock Index (Ghosh and Clayton, 1996), Fixed-income (Ahmed, 2007), Metals (Baillie and Myers, 1991), Agriculture (Sephton, 1993), Power (Bystrom, 2003; Ripple and Moosa, 2007) and among many others. In carbon market, Chevallier's (2008) studied Phase I of the EU-ETS extensively, with the emphasis on banking, pricing and risk hedging strategies. However, under the risk hedging section, the possible use of the optimal hedge ratio is yet to be discussed. Cetin and Verschuere (2009) proposed hedging formulas using a local risk minimisation approach, but again, hedging with carbon futures contracts or other derivatives are not considered.

The distinctiveness and novelty of the carbon market, however, provided a compelling motivation to re-estimate the hedge ratio in this market. The results showed that the magnitude and hedging performance of the optimal hedge ratio obtained for the carbon market are in line with those obtained for other markets. These results can be an indication that, in spite of the uniqueness of the carbon market, the tools, techniques, theories and concepts in finance can still be applied in the analysis of such markets, subject of course to certain modifications. This should be a welcome development for financial market players such as 
institutional investors, portfolio managers, traders and speculators as this should provide them encouragement to participate in the carbon market.

This paper consists of six main sections. Section 2 provides an institutional setting for the EU-ETS carbon market. In Section 3 the concept of hedge ratio is introduced. In Section 4 the methodology of the estimation of hedge ratios in the carbon market is presented. Section 5 provides estimation results accompanied by an extensive discussion. This is followed by a comparison of estimated hedge ratios in the carbon market to other markets. The paper is concluded in Section 6.

\section{Institutional Setting}

The European Union Emissions Trading Scheme is the world's largest multi-country, multi-sector mandatory greenhouse gas emissions trading regime. There are 27 member states currently under the scheme. It covers $\mathrm{CO} 2$ emissions from electricity generation and the main energy-intensive industries including power stations, refineries and offshore oil and gas production, iron and steel, cement and lime, paper, food and drink, glass, ceramics, engineering and auto manufacturing (Directive 2003/87/EC, 2003). Fundamentally, as a cap-and-trade program, EU-ETS operates by placing a cap or limit on the amount of $\mathrm{CO} 2$ companies can emit every year. Each company is awarded an annual quota of carbon dioxide emission units where 1 unit of allowance $=1$ ton of $\mathrm{CO} 2$ (one unit of EUA). Firms that emit more than their allocated allowance can choose

to pay the non-compliance penalty or purchase surplus allowance from 
companies that manage to stay below their limit. The system is designed to cut CO2 emissions in a cost effective way. In addition, over time, the total number of quotas/allowances is to be reduced, which will lead to an increase in the price of carbon emissions allowances due to the scarcity of supply.

The allocation of EUA is determined by each individual country's Nation Allocation Plan (NAP). Each country designs its own NAP according to its emissions produced from different sectors and other relevant characteristics. Before distributing these allowances to firms and organizations, the NAP has to be reported to the EU Commission for approval.

Commencing operation in January 2005, there are three phases set out in EU-ETS, Phase I (2005-2007), Phase II (2008 - 2012) and Phase III (2013-2020). Phase I is an experimental scheme; it started with six key industrial sectors, namely energy activities production and processing of ferrous metals, mineral industry and pulp, paper and board activities. In Phase II, coverage is broadened, so that in addition to Phase I, CO2 emissions from glass, mineral, wool, gypsum, flaring from offshore oil and gas production, petrochemicals, carbon black and integrated steel works are included. In Phase III, an EU-wide cap is proposed to replace the current system of NAPs set by each member state, and the overall cap will be further tightened on an annual basis.

Banking of allowances means the carrying forward of the unused emission allowances from the current year for use in the following year. The banking of 
allowances is permitted within Phases (except for France and Poland), however it was prohibited from 2007 to 2008 (inter-phase). This had significant implications for the pricing of emission allowance and its underlying derivatives. However, industries are allowed to bank the unused permit from Phase II to Phase III. Financial penalties apply when emitters do not meet their compliance requirements. Moreover, all credit deficiencies must be purchased in addition to fines paid. An independent third party must audit all the reported emissions.

There are currently three major market exchanges in operation to facilitate EU-ETS trading, namely the BlueNext, Nordpool and the European Climate Exchange (ECX). We use spot EUA contracts from BlueNext (based in Paris) and futures contracts from ECX (based in London) for hedge ratio calculation and effectiveness measurement. One lot of both the spot and futures contract covers 1,000 tonnes of $\mathrm{CO} 2$ and there is a 3-day delivery period after the trading day for futures contracts.

\section{Hedging and Hedge Ratios}

Hedging is an investment made to mitigate the price risk (unfavourable fluctuation) of the underlying assets at maturity. A futures contract is a dominant instrument used in hedging, mainly because of its transparency and liquidity advantages over the others. The hedging is primarily implemented by using a hedge ratio, which determines the portions of the spot that need to be hedged in order to achieve a minimum level of unfavourable price fluctuation (Ederington, 
1979; Johnson, 1960; Myers and Thompson, 1989).

Following Hatemi-J and Roca (2006), we define the optimal hedge ratio as the quantities of the spot instrument and the hedging instrument that ensure that the total value of the hedged portfolio does not change. It can be formally expressed in terms of the following:

$$
\begin{aligned}
& V_{h}=Q_{s} S-Q_{f} F \\
& \Delta V_{h}=Q_{s} \Delta S-Q_{f} \Delta F
\end{aligned}
$$

Where $V_{h}$ is the value of the hedged portfolio, $Q_{s}$ and $Q_{f}$ are the quantity of spot and futures instrument respectively, $S$ and $F$ are the price of spot and futures instrument respectively,

$$
\begin{gathered}
\text { If } \Delta V_{h}=0 \text {, then } \frac{Q_{f}}{Q_{s}}=\frac{\Delta S}{\Delta F} \\
\text { Let } h=\frac{Q_{f}}{Q_{s}} \Rightarrow h=\frac{\Delta S}{\Delta F}
\end{gathered}
$$

where $h$ gives the hedge ratio.

Therefore, the hedge ratio can be demonstrated as the slope coefficient in a regression of the price of the spot instrument on the price of the future (hedging) instrument.

However, this also depends on the objective function of the hedger. Minimum variance is the most popular and widely used approach, although this has been criticized for not taking into account the expected return which is inconsistent with the mean-variance framework. Since the selection of a hedge ratio is dependent on the hedgers' objective in the hedging position, this will be different for various 
participants in the carbon market. For example, investors not only desire to protect the investment portfolio from carbon price risk but also need to ensure their returns at the same time. Therefore, the objective function of hedging under such circumstances should not be solely based on minimum variance. However, the objective of risk management for emitters in the market does not necessarily have to be the same as investors' objectives. Because of its compulsory participation, the priority of risk management should be given to hedging of the carbon price risk. Accordingly, the objective function for them can be (but not limited to) the achievement of a minimum variance of the hedged portfolio.

Optimal hedge ratio estimations have been conducted extensively since the introduction of futures contracts. There are various techniques suggested by many researchers and studies in various markets not limited to traditional financial markets.

\section{Methodology}

\subsection{Hedge Ratio Estimation and Evaluation of Hedging Effectiveness}

This paper applies hedge ratio estimation models which have been widely used in calculating hedge ratios in other markets. These are the naive approach, the ordinary least squares (OLS), the error correction model (ECM), and the generalized autoregressive conditional heteroscedasticity models (GARCH).

The effectiveness of each estimated hedge ratio is assessed based on two criteria: (a) variance reduction, and (b) utility maximization. To calculate the 
percentage variance reduction, the difference in variance of the unhedged portfolio and each hedged portfolio (constructed using different hedge ratios resulted from diverse models) is divided by the variance of the unhedged portfolio. To estimate variance reduction in a natural number the following equation is used:

$$
\operatorname{VAR}\left(\Delta S_{t}\right)-\operatorname{VAR}\left(\Delta S_{t}-h^{*} \Delta F_{t}\right)
$$

The utility maximization method incorporates the risk aversion of investors. Using this method, the level of investors' utility that computed differently from the hedged portfolio is compared and ranked by the degree of utility improvement from the unhedged portfolio. This method now satisfies the mean-variance framework because it does not assess the minimum variance but also takes into consideration the return of the hedged portfolio. The objective function that maximizes the utility is given as:

$$
\operatorname{MAX}\left[E\left(R_{h} \mid \Omega_{t-1}\right)-\frac{1}{2} \phi \operatorname{Var}\left(R_{h} \mid \Omega_{t-1}\right)\right]
$$

where $R_{h}$ is the hedged portfolio $\left(\Delta S_{t}-h^{*} \Delta F\right), E\left(R_{h}\right)$ is the return of the hedged portfolio, $\operatorname{Var}\left(R_{h}\right)$ is the variance of the hedged portfolio, $\phi$ is the investors' level of risk aversion, $\Omega_{t-1}$ is the information set at time $\mathrm{t}-1$.

The utility level for the hedged and unhedged portfolio is computed from the portfolio's mean and variance of return.

\subsection{Data and Diagnostic Tests}

The data used in this study consists of spot (cash) and futures contracts of the 
respective carbon trading instruments. One ton of carbon dioxide permit equals one unit of EUA - the spot EUA data is drawn from BlueNext exchange. In line with Phases set by policy makers, our data is divided into two periods which are referred to as BNS EUA 05-07 (Phase I BlueNext Spot EUA 05-07) from 24/06/2005 to 25/04/2008 and BNS EUA 08-12 (Phase II BlueNext Spot EUA 08-12) from $26 / 02 / 2008$ to $18 / 12 / 2009$. To match the hedging horizon and the maturity of the futures contract, the spot EUA dataset is subdivided into a number of periods.

Data on the futures contract is drawn from the ECX (European Climate Exchange), known as the ICE/ECX EUA futures contract. ECX offers futures contracts on EUA for different maturities; they are sorted as Dec-05, Dec-06, Dec-07, Dec-08, Dec-09, etc. To match the spot EUA data, this paper uses the ECX futures contract up to Dec-09 maturity. All spot and futures data mentioned above are historical daily closing prices.

To mitigate the liquidity concerns, we have used futures contract that is expiring at the nearest date. In Phase I of the EU-ETS, only contracts with yearly expiration cycle were available for trade, whereas in Phase II, contracts that expire on a quarterly basis became tradable. However, the quarterly expiring contracts in Phase II (i.e. Jan-08, Mar-08, Sep-08, Jan-09, Mar-09, Sep-09), had severe liquidity issues as there was little or no trading volumes at all. Therefore, the most liquid contracts with yearly expiration for both Phases I and II hedge ratios 
estimation are used, with each contract maturing in December from 2005 to 2009.

The following figure demonstrates the historical trading volume of two contracts expiring in December 2008 and 2009 respectively:

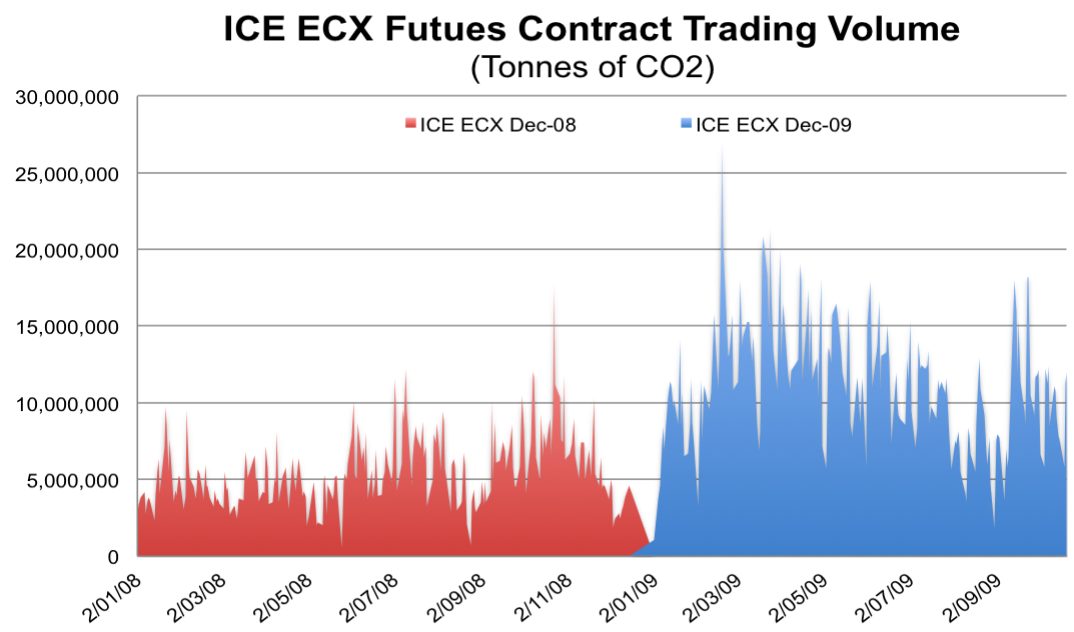

Figure 1. ICE ECX Futures Contract Trading volume

As shown in Figure 1, on average there are more than eight million tonnes of $\mathrm{CO} 2$ futures contract being traded on a daily basis. With this clear increasing trend of liquidity, the Dec-08 and Dec-09 contracts should be sufficient to eliminate any liquidity concerns.

\section{Empirical Results and Discussion}

In this section, the findings of our empirical analysis are discussed. Firstly, descriptive statistics and the results of diagnostic tests are presented. Secondly, the estimated optimal hedge ratios are reported. Thirdly, the effectiveness of the hedging ratios is presented. Lastly, these hedge ratios are compared with those obtained in various markets.

\subsection{Descriptive statistics and diagnostic tests}


Table 1 provides the descriptive statistics for spot and futures of EUA. There are two panels in the table, panel A reports the results on the original price level and panel B reports the returns level. The following Table 1 shows that all series are characterized by non-normalities.

Table 1. Descriptive statistics

\begin{tabular}{|c|c|c|c|c|c|c|c|c|c|c|}
\hline & bs. & Mean & Median & Max. & Min. & Std. Dev. & Skewness & Kurtosis & $\mathrm{J}-\mathrm{B}$ & Prob. \\
\hline \multicolumn{11}{|c|}{ Panel A: Price Level } \\
\hline EUA & \multirow{2}{*}{120} & 22.619 & 22.140 & 28.930 & 18.850 & 2.012 & 1.490 & 5.645 & 79.369 & 0.000 \\
\hline Dec-05 & & 22.628 & 22.200 & 29.100 & 19.500 & 2.060 & 1.532 & 5.697 & 83.302 & 0.000 \\
\hline EUA & \multirow{2}{*}{237} & 17.618 & 16.000 & 29.750 & 6.400 & 6.606 & 0.269 & 1.840 & 16.150 & 0.000 \\
\hline Dec-06 & & 17.960 & 16.300 & 30.450 & 6.400 & 6.837 & 0.273 & 1.842 & 16.188 & 0.000 \\
\hline EUA & \multirow{2}{*}{246} & 0.675 & 0.120 & 5.480 & 0.030 & 1.096 & 2.443 & 8.435 & 547.537 & 0.000 \\
\hline Dec-07 & & 0.695 & 0.140 & 5.600 & 0.010 & 1.107 & 2.411 & 8.283 & 524.459 & 0.000 \\
\hline EUA & \multirow{2}{*}{206} & 22.671 & 23.370 & 28.730 & 13.700 & 3.476 & -0.817 & 2.956 & 22.919 & 0.000 \\
\hline Dec-08 & & 22.908 & 23.610 & 29.330 & 13.720 & 3.559 & -0.824 & 3.018 & 23.306 & 0.000 \\
\hline EUA & \multirow{2}{*}{244} & 13.158 & 13.510 & 15.490 & 7.960 & 1.599 & -1.145 & 3.827 & 60.254 & 0.000 \\
\hline Dec-09 & & 13.365 & 13.725 & 15.870 & 8.200 & 1.567 & -1.142 & 4.009 & 63.421 & 0.000 \\
\hline \multicolumn{11}{|c|}{ Panel B: First Difference } \\
\hline EUA & \multirow{2}{*}{119} & -0.018 & 0.050 & 2.350 & -3.450 & 0.697 & -1.062 & 8.443 & 169.275 & 0.000 \\
\hline Dec-05 & & -0.021 & 0.050 & 2.350 & -3.300 & 0.690 & -1.573 & 10.836 & 353.520 & 0.000 \\
\hline EUA & \multirow{2}{*}{236} & -0.064 & 0.010 & 3.510 & -8.600 & 0.885 & -3.843 & 41.273 & 14984.830 & 0.000 \\
\hline Dec-06 & & -0.067 & 0.000 & 5.800 & -7.150 & 0.891 & -1.589 & 28.602 & 6544.883 & 0.000 \\
\hline EUA & \multirow{2}{*}{245} & -0.022 & 0.000 & 0.280 & -0.960 & 0.106 & -4.210 & 32.388 & 9539.924 & 0.000 \\
\hline Dec-07 & & -0.023 & 0.000 & 0.350 & -0.850 & 0.111 & -3.698 & 25.129 & 5557.353 & 0.000 \\
\hline EUA & \multirow{2}{*}{205} & -0.027 & 0.000 & 1.220 & -1.660 & 0.521 & -0.596 & 3.837 & 18.118 & 0.000 \\
\hline Dec-08 & & -0.030 & 0.010 & 1.100 & -1.720 & 0.521 & -0.562 & 3.422 & 12.302 & 0.002 \\
\hline EUA & \multirow{2}{*}{243} & -0.001 & 0.000 & 0.990 & -0.940 & 0.363 & -0.003 & 2.931 & 0.049 & 0.976 \\
\hline Dec-09 & & -0.005 & -0.020 & 1.130 & -0.970 & 0.371 & 0.095 & 3.109 & 0.485 & 0.785 \\
\hline
\end{tabular}

We tested for stationarity of each series based on the, Augmented Dickey-Fuller (ADF) and Philips-Perron (PP) tests. We found that all series are nonstationary. We then conducted a cointegration test between the spot and future prices corresponding to different expiration dates - from December 2005 to December 2009 using the Engle-Granger and the Johansen methodologies. The results 
show that the spot and future prices for all the different expiry dates are cointegrated $^{2}$

\subsection{Hedge Ratios by different models in EU-ETS carbon market}

Sorted by models, Table 2 contains a summary of hedge ratio for different hedging horizons. Hedge ratios computed using Naive, OLS, ECM and VECM (Vector ECM) models are fixed, in other words time-invariant hedge ratios. All of them remain unchanged throughout the entire hedging horizons (i.e. Phase I and II). By contrast, since VECM-GARCH produces time-varying hedge ratio, results of VECM-GARCH reported in Table 2 are the averaged value of the dynamic, time-varying hedge ratios at each point in time in order to allow these to be compared with the other hedge ratios obtained from the other models.

As can be seen from Table 2, hedge ratios $(\mathrm{OHR})$ vary from model to model and from period to period. Firstly, the calculated hedge ratio for two-stage ECM and VECM are extremely close to each other in most cases. This is not surprising given that they share the same error correction fundamentals. However, this minor difference may generate implications for hedge ratio performance evaluations as OHR is one of the inputs for performance calculation. Secondly, in Phase II, all OHRs declined in 2009, compared to the 2008 hedging horizon. Thirdly, Phase II OHRs are generally greater than those of Phase I; this can be explained by the lower overall variance of futures price changes in Phase II as

\footnotetext{
2 These test results are not reported due to space limitations but available upon request.
} 
compared to Phase I.

Table 2. Calculated Hedge Ratios

\begin{tabular}{|c|c|c|c|c|c|c|c|}
\hline Phase & $\begin{array}{l}\text { Hedging } \\
\text { Horizon }\end{array}$ & $\begin{array}{l}\text { Futures } \\
\text { Contract }\end{array}$ & $\begin{array}{c}\text { Naive } \\
\text { Apporch }\end{array}$ & $\begin{array}{l}\text { Simple } \\
\text { OLS }\end{array}$ & $\begin{array}{c}\text { Two-stage } \\
\text { ECM }\end{array}$ & $\begin{array}{c}\text { Vector } \\
\text { ECM }\end{array}$ & $\begin{array}{c}\text { VECM } \\
\text { GARCH }^{*}\end{array}$ \\
\hline \multirow{3}{*}{ 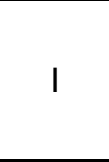 } & $24 / 6 / 05-19 / 12 / 05$ & Dec-05 & 1.0000 & 0.8556 & 0.7683 & 0.7743 & 0.7157 \\
\hline & 3/1/06-8/12/06 & Dec-06 & 1.0000 & 0.8533 & 0.7016 & 0.6801 & 0.8740 \\
\hline & 2/1/07-7/12/07 & Dec-07 & 1.0000 & 0.8962 & 0.9331 & 0.9099 & 0.5565 \\
\hline \multirow[t]{2}{*}{$\|$} & $26 / 2 / 08-11 / 12 / 08$ & Dec-08 & 1.0000 & 0.9557 & 0.9666 & 0.9666 & 0.9792 \\
\hline & 2/1/09-9/12/09 & Dec-09 & 1.0000 & 0.8794 & 0.9444 & 0.9384 & 0.9379 \\
\hline
\end{tabular}

* note that hedge ratios listed in table are averaged values

\subsection{Hedging Effectiveness}

This section reports on two aspects of the performance of the estimated hedge ratios. The first part of this section reports the results of the variance reduction by employing different models over the unhedged position. The second part adopts the maximum utility technique. The utility improvements of each model over the unhedged position are reported separately for each hedging combination.

\section{Variance Reduction}

Table 3 reports the results of variance reduction for each hedging combination achieved using Naive, OLS, ECM, VECM and VECM-GARCH models. The variance reduction for each hedging combination is presented in two rows. The first row represents the variance reduction in natural numbers, whereas the second row shows percentage variance reduction over the unhedged position. 
Table 3. Variance Reduction Based on Different Models

\begin{tabular}{|c|c|c|c|c|c|c|c|c|}
\hline \multirow[t]{2}{*}{ Phase } & \multirow{2}{*}{$\begin{array}{c}\text { Hedging } \\
\text { Horizon }\end{array}$} & \multirow{2}{*}{$\begin{array}{l}\text { Futures } \\
\text { Contract }\end{array}$} & \multirow{2}{*}{$\begin{array}{l}\text { Variance } \\
\text { Unhedged }\end{array}$} & \multicolumn{5}{|c|}{ Hedged Portfolio Variance Based On } \\
\hline & & & & Naive & OLS & ECM & VECM & VECM-GARCH \\
\hline \multirow{9}{*}{ I } & 2005 & Dec-05 & 0.4862 & 0.14801 & 0.13809 & 0.14171 & 0.14123 & 0.19013 \\
\hline & & \multirow{2}{*}{ Variance } & \multirow{2}{*}{ e Reduced } & $\underline{0.33820}$ & $\underline{0.34812}$ & $\underline{0.34450}$ & $\underline{0.34498}$ & $\underline{0.29609}$ \\
\hline & & & & $\underline{\underline{69.56 \%}}$ & $\underline{\underline{71.60 \%}}$ & $\underline{\underline{70.85 \%}}$ & $\underline{\underline{70.95 \%}}$ & $\underline{\underline{60.90 \%}}$ \\
\hline & 2006 & Dec-06 & 0.7927 & 0.22498 & 0.20767 & 0.22616 & 0.23177 & 0.28203 \\
\hline & & \multirow{2}{*}{\multicolumn{2}{|c|}{ Variance Reduced }} & $\underline{0.56772}$ & $\underline{0.58503}$ & $\underline{0.56655}$ & $\underline{0.56093}$ & $\underline{0.51068}$ \\
\hline & \multirow{4}{*}{2007} & & & $\underline{\underline{71.62 \%}}$ & $\underline{\underline{73.80 \%}}$ & $\underline{\underline{71.47 \%}}$ & $\underline{\underline{70.76 \%}}$ & $\underline{\underline{64.42 \%}}$ \\
\hline & & Dec-07 & 0.0112 & 0.00141 & 0.00130 & 0.00174 & 0.00185 & 0.00101 \\
\hline & & & $\mathrm{Reo}$ & $\underline{0.00984}$ & $\underline{0.00995}$ & $\underline{0.00950}$ & $\underline{0.00939}$ & $\underline{0.01024}$ \\
\hline & & & & $\underline{\underline{87.49 \%}}$ & $\underline{\underline{88.48 \%}}$ & $\underline{\underline{84.50 \%}}$ & $\underline{\underline{83.52 \%}}$ & $\underline{\underline{91.01 \%}}$ \\
\hline & 2008 & Dec-08 & 0.2705 & 0.02469 & 0.02415 & 0.02419 & 0.02419 & 0.02435 \\
\hline & \multirow{5}{*}{2009} & \multirow{2}{*}{\multicolumn{2}{|c|}{ Variance Reduced }} & $\underline{0.24582}$ & $\underline{0.24635}$ & $\underline{0.24632}$ & $\underline{0.24632}$ & $\underline{0.24616}$ \\
\hline & & & & $\underline{90.87 \%}$ & $91.07 \%$ & $\underline{91.06 \%}$ & $\underline{91.06 \%}$ & $91.00 \%$ \\
\hline & & Dec-09 & 0.1316 & 0.02720 & 0.02520 & 0.02578 & 0.02568 & 0.02614 \\
\hline & & \multirow{2}{*}{\multicolumn{2}{|c|}{ Variance Reduced }} & $\underline{0.10440}$ & $\underline{0.10640}$ & $\underline{0.10581}$ & $\underline{0.10592}$ & $\underline{0.10545}$ \\
\hline & & & & $79.33 \%$ & $80.85 \%$ & $80.41 \%$ & $\underline{\underline{80.49 \%}}$ & $80.14 \%$ \\
\hline
\end{tabular}

As evident from Table 3, all models have produced significant variance reduction over the unhedged position across the entirety of Phases I and II hedging horizons. The smallest reduction is greater than 60 percent of the unhedged position. Meanwhile, the largest reduction (91 percent) indicates a variance reduction of nearly a hundred percent. Thus, hedging with futures contracts has significantly reduced the risk (variance, in this case) of unhedged trading in spot EUAs. However, the performance of individual hedge ratio estimation models is mixed, thus a single conclusion on the superiority of a certain model cannot be drawn with confidence. Instead, a generalized result which attempts to consolidate the results will be discussed. The following frequency distribution table is designed to pool the output. The performance of each model in terms of variance reduction is ranked within the seven hedging horizons (see Table 4). 
Table 4. Frequency Distribution Chart for Ranking of Variance Reduction

\begin{tabular}{ccccccc|c}
\hline & Rank 1 & Rank 2 & Rank 3 & Rank 4 & Rank 5 & Overall Rank \\
\hline Naïve & 0 & 0 & 2 & 1 & 2 & Fifth \\
OLS & 4 & 1 & 0 & 0 & 0 & First \\
ECM & 0 & 1 & 2 & 2 & 0 & Third \\
VECM & 0 & 2 & 2 & 0 & 1 & Second \\
VECM-GARCH & 1 & 0 & 0 & 2 & 2 & Fourth \\
\hline
\end{tabular}

In contrast to some existing research, this study does not support the superiority of the VECM-GARCH model. As shown in Table 4, the VECM-GARCH has been ranked the worst on two occasions. The conventional OLS is ranked as the best performing model in four cases, clearly outperforming all other models in overall ranking. Moreover, it is not surprising to see that frequency rankings and variance reduction of ECM and VECM are close to each other since they share the same foundation of error correction mechanisms. Also notable is that the difference in variance reduction between OLS and ECMs is relatively small (within 0.8 percent). The naive model together with the VECM-GARCH model is the worst performer in the overall ranking. Despite the difference in overall result, variance reductions achieved using Naive, OLS, ECMs are very close to each other, with differences of less than 3.5 percent in all hedging combinations. Most notably, although the Naive model provides near-worst a result, the variance reduction is not too far away from OLS and ECMs. This can be used as an argument for full hedge, as the easiest hedging strategy. However, variance reduction achieved by the VECM-GARCH model in all Phase I hedging combinations appears to be much lower than the others (over 10 percent difference). In Phase II hedging 
combinations, such difference becomes much smaller.

In addition, unlike a fixed OHR where the hedged portfolio remains unchanged across the hedging horizon, the VECM-GARCH derived conditional optimal hedge ratio changes over time. Thus, the explicit transaction cost of rebalancing the hedged portfolio will have to be included if this is used in practice. Therefore, based on the result in this study (worst variance reduction) and taking into account transaction costs, the utility of VECM-GARCH in the EU-ETS market over the studied period is seriously questioned. Such findings are in line with Bystrom (2003), Copeland and Zhu (2006), Lien et al. (2002) and Moosa (2003), where OLS was found to outperform the more complex and sophisticated models. Later in Lien (2007), it is shown that, in large sample cases, the conventional hedge ratio provides the best performance, whereas for small sample cases a sufficiently large variation in the dynamic variance of the futures return is required in order for dynamic models to produce favourable variance reduction. It is also worth noting that the hedging effectiveness measure is based upon the unconditional variance. The conventional hedge ratio aims to minimize the time-invariant variance while the conditional hedge ratio attempts to minimize the dynamic variance. The pure variance reduction approach of performance evaluation is criticized for not taking into account utility. Therefore the next section incorporates the utility factor into the modelling. 


\section{Maximum Utility}

Adopting the procedures discussed in the methodology section, Table 5 provides the utility improvements which have resulted from using different models with a risk aversion ranging from 1 to 3 . Results of each hedging horizon are reported separately in chronological order. Similar with variance reduction, the utility improved over the unhedged position is presented both in natural numbers and percentages. 
Table 5. Utility Improvement Based on Different Models

\begin{tabular}{|c|c|c|c|c|c|c|c|}
\hline \multirow{2}{*}{$\begin{array}{l}\text { Hedging } \\
\text { Horzion }\end{array}$} & \multirow{2}{*}{$\begin{array}{l}\text { Futures } \\
\text { Contract }\end{array}$} & \multirow{2}{*}{$\begin{array}{c}\text { Utility } \\
\text { Unhedged }\end{array}$} & \multicolumn{5}{|c|}{ Utility Improvement Based On } \\
\hline & & & Naive & OLS & ECM & VECM & VECM-GARCH \\
\hline \multicolumn{8}{|c|}{ Risk Aversion $=1$} \\
\hline \multirow[t]{3}{*}{2005} & Dec-05 & -0.2608 & -0.0702 & -0.0684 & -0.0720 & -0.0717 & -0.1189 \\
\hline & \multirow{2}{*}{\multicolumn{2}{|c|}{ Utility Improved }} & $\underline{0.1905}$ & $\underline{0.1924}$ & $\underline{0.1887}$ & $\underline{0.1891}$ & $\underline{0.1418}$ \\
\hline & & & $73.07 \%$ & $73.78 \%$ & $72.37 \%$ & $72.51 \%$ & $54.39 \%$ \\
\hline \multirow[t]{3}{*}{2006} & Dec-06 & -0.4623 & -0.1102 & -0.1116 & -0.1312 & -0.1354 & -0.1771 \\
\hline & \multirow{2}{*}{\multicolumn{2}{|c|}{ Utility Improved }} & $\underline{0.3521}$ & $\underline{0.3507}$ & $\underline{0.3311}$ & $\underline{0.3269}$ & $\underline{0.2852}$ \\
\hline & & & $76.16 \%$ & $75.87 \%$ & $71.63 \%$ & $70.70 \%$ & $61.68 \%$ \\
\hline \multirow[t]{3}{*}{2007} & Dec-07 & -0.0278 & -0.0001 & -0.0034 & -0.0071 & -0.0076 & -0.0021 \\
\hline & \multirow{2}{*}{\multicolumn{2}{|c|}{ Utility Improved }} & $\underline{0.0277}$ & $\underline{0.0244}$ & $\underline{0.0208}$ & $\underline{0.0202}$ & $\underline{0.0258}$ \\
\hline & & & $99.67 \%$ & $87.84 \%$ & $74.60 \%$ & $72.64 \%$ & $92.62 \%$ \\
\hline \multirow[t]{3}{*}{2008} & Dec-08 & -0.1618 & -0.0094 & -0.0105 & -0.0102 & -0.0102 & -0.0094 \\
\hline & \multirow{2}{*}{\multicolumn{2}{|c|}{ Utility Improved }} & $\underline{0.1524}$ & $\underline{0.1514}$ & $\underline{0.1517}$ & $\underline{0.1517}$ & $\underline{0.1524}$ \\
\hline & & & $94.18 \%$ & $93.54 \%$ & $93.73 \%$ & $93.73 \%$ & $94.16 \%$ \\
\hline \multirow[t]{3}{*}{2009} & Dec-09 & -0.0669 & -0.0099 & -0.0095 & -0.0095 & -0.0094 & -0.0152 \\
\hline & Utilitv & Imnroved & $\underline{0.0571}$ & $\underline{0.0575}$ & $\underline{0.0575}$ & $\underline{0.0575}$ & $\underline{0.0517}$ \\
\hline & Utinty & y improved & $85.22 \%$ & $85.84 \%$ & $85.88 \%$ & $85.91 \%$ & $77.27 \%$ \\
\hline \multicolumn{8}{|c|}{ Risk Aversion $=2$} \\
\hline \multirow[t]{3}{*}{2005} & Dec-05 & -0.5039 & -0.1442 & -0.1374 & -0.1429 & -0.1423 & -0.2140 \\
\hline & & Imnround & $\underline{0.3596}$ & $\underline{0.3665}$ & $\underline{0.3610}$ & $\underline{0.3616}$ & $\underline{0.2899}$ \\
\hline & Uitily & y improved & $71.38 \%$ & $72.73 \%$ & $71.64 \%$ & $71.76 \%$ & $57.53 \%$ \\
\hline \multirow[t]{3}{*}{2006} & Dec-06 & -0.8587 & -0.2227 & -0.2154 & -0.2442 & -0.2513 & -0.3182 \\
\hline & Utility & & $\underline{0.6360}$ & $\underline{0.6433}$ & $\underline{0.6144}$ & $\underline{0.6073}$ & $\underline{0.5405}$ \\
\hline & & y improved & $74.06 \%$ & $74.91 \%$ & $71.55 \%$ & $70.73 \%$ & $62.95 \%$ \\
\hline \multirow[t]{3}{*}{2007} & Dec-07 & -0.0335 & -0.0008 & -0.0040 & -0.0079 & -0.0085 & -0.0026 \\
\hline & & & $\underline{0.0327}$ & $\underline{0.0294}$ & $\underline{0.0255}$ & $\underline{0.0249}$ & $\underline{0.0309}$ \\
\hline & Utillty & y improved & $97.63 \%$ & $87.95 \%$ & $76.26 \%$ & $74.47 \%$ & $92.35 \%$ \\
\hline \multirow[t]{3}{*}{2008} & Dec-08 & -0.2971 & -0.0218 & -0.0225 & -0.0222 & -0.0222 & -0.0216 \\
\hline & Itility & Imnroved & $\underline{0.2753}$ & $\underline{0.2746}$ & $\underline{0.2748}$ & $\underline{0.2748}$ & $\underline{0.2755}$ \\
\hline & Uinty & y improved & $92.68 \%$ & $92.42 \%$ & $92.51 \%$ & $92.51 \%$ & $92.72 \%$ \\
\hline \multirow[t]{3}{*}{2009} & Dec-09 & -0.1327 & -0.0235 & -0.0221 & -0.0223 & -0.0223 & -0.0283 \\
\hline & & & $\underline{0.1093}$ & $\underline{0.1107}$ & $\underline{0.1104}$ & $\underline{0.1105}$ & $\underline{0.1045}$ \\
\hline & UtIll & y Improved & $82.30 \%$ & $83.37 \%$ & $83.17 \%$ & $83.22 \%$ & $78.69 \%$ \\
\hline & & & & Aversion & & & \\
\hline 2005 & Dec-05 & -0.7470 & -0.2182 & -0.2064 & -0.2138 & -0.2129 & -0.3090 \\
\hline & Itility & Imnroved & $\underline{0.5287}$ & $\underline{0.5405}$ & $\underline{0.5332}$ & $\underline{0.5341}$ & $\underline{0.4379}$ \\
\hline & Uinty & y improved & $70.78 \%$ & $72.36 \%$ & $71.38 \%$ & $71.50 \%$ & $58.63 \%$ \\
\hline 2006 & Dec-06 & -1.2550 & -0.3352 & -0.3193 & -0.3573 & -0.3672 & -0.4592 \\
\hline & Utility & v Improved & $\underline{0.9198}$ & $\underline{0.9358}$ & $\underline{0.8977}$ & $\underline{0.8878}$ & $\underline{0.7959}$ \\
\hline & & & $73.29 \%$ & $74.56 \%$ & $71.53 \%$ & $70.74 \%$ & $63.41 \%$ \\
\hline 2007 & Dec-07 & -0.0391 & -0.0015 & -0.0047 & -0.0088 & -0.0095 & -0.0031 \\
\hline & Utility & Imnroud & $\underline{0.0376}$ & $\underline{0.0344}$ & $\underline{0.0303}$ & $\underline{0.0296}$ & $\underline{0.0360}$ \\
\hline & Utinty & y improved & $96.17 \%$ & $88.02 \%$ & $77.45 \%$ & $75.77 \%$ & $92.16 \%$ \\
\hline 2008 & Dec-08 & -0.4323 & -0.0341 & -0.0346 & -0.0343 & -0.0343 & -0.0338 \\
\hline & Utilitv & Imnroved & $\underline{0.3982}$ & $\underline{0.3977}$ & $\underline{0.3980}$ & $\underline{0.3980}$ & $\underline{0.3985}$ \\
\hline & & & $92.11 \%$ & $91.99 \%$ & $92.06 \%$ & $92.06 \%$ & $92.18 \%$ \\
\hline 2009 & Dec-09 & -0.1985 & -0.0371 & -0.0347 & -0.0352 & -0.0351 & -0.0414 \\
\hline & & & $\underline{0.1614}$ & $\underline{0.1639}$ & $\underline{0.1633}$ & $\underline{0.1634}$ & $\underline{0.1572}$ \\
\hline & Un & y improved & $81.32 \%$ & $82.53 \%$ & $82.25 \%$ & $82.32 \%$ & $79.17 \%$ \\
\hline
\end{tabular}


As can be seen in Table 5, under different level of investor's risk aversion the results of utility improvement achieved by different models are mixed. Table 6 reports the frequency distribution of the utility improvement rankings under the risk aversion ranging from 1 to 3 .

Table 6. Frequency Distribution Chart for Ranking of Utility Improvement

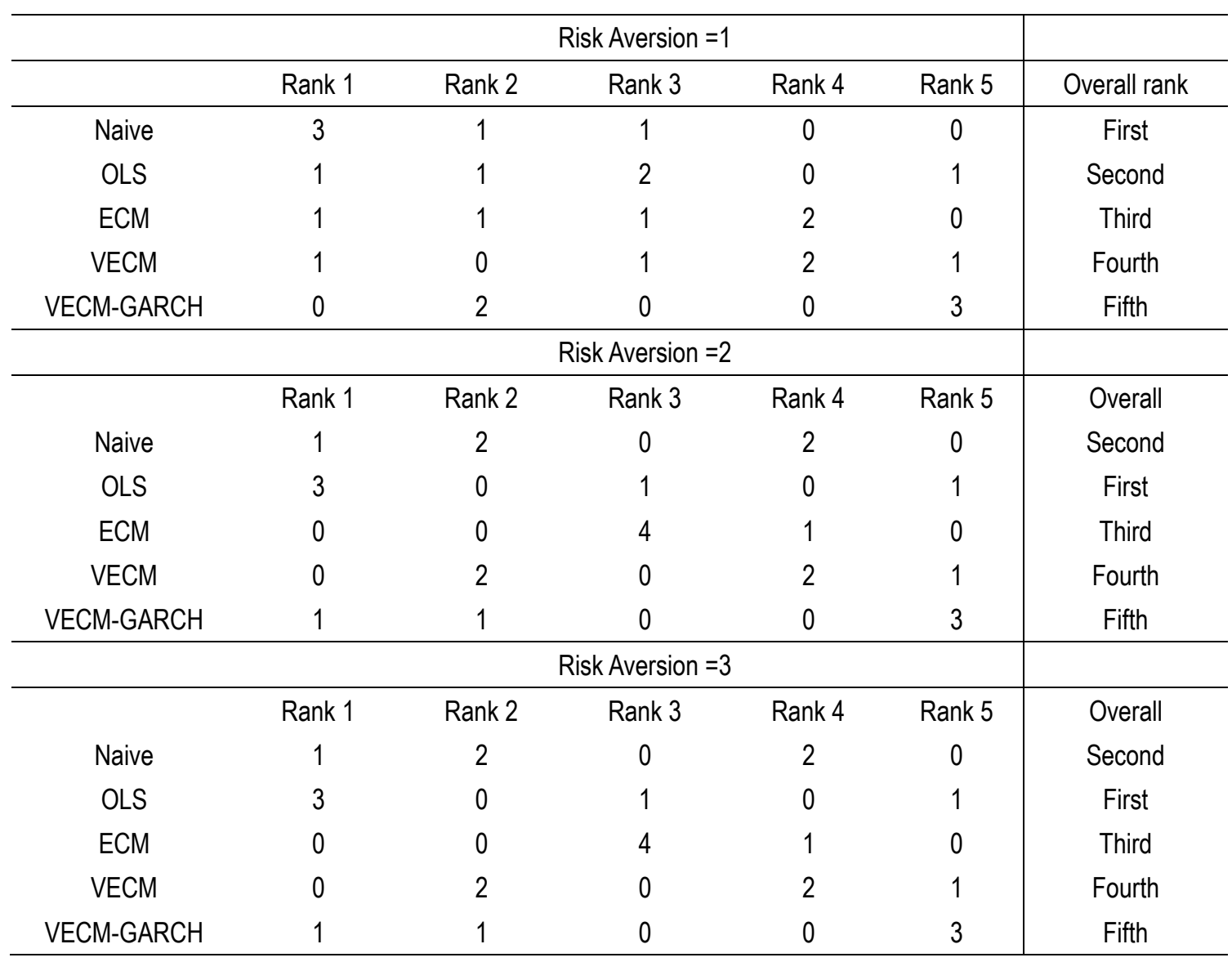

As observed in Table 6 with risk aversion set at 1 , the model which most frequently produces the highest utility improvement over the unhedged position is the Naïve model. Under risk aversions 2 and 3, OLS demonstrated the best overall performance. This result confirms findings based on variance reduction 
capabilities, which in turn suggests robustness of the findings. At all levels of risk aversion, OHR derived by VECM GARCH most frequently produces the lowest utility improvement. As the risk aversion level increases from 1 to 3 , utility improvement based on OLS decreases. This is in line with the in-sample results in Yang \& Allen (2004). By contrast, utility improvement achieved by VECM-GARCH presents a mixture of results when the risk aversion increases gradually. In some cases it increases, while it decreases in other cases.

\subsection{Comparisons of Carbon Hedge Ratios to Those in Other Markets}

Table 7 lists hedge ratios derived using OLS, ECM and GARCH models in various existing markets. It should be noted here that, the hedge ratios in the GARCH column are presented as averages. These ratios are then compared with EUA vs. Dec-09 hedge ratios with the hedging horizon from 2008 to 2009 up to 20/12/2009. 
Table 7. Comparison of Carbon Hedge Ratios with those in other markets

\begin{tabular}{|c|c|c|c|c|c|}
\hline Category & Commodity & OLS & ECM & $\mathrm{GARCH}^{*}$ & $\mathrm{ECM}+\mathrm{GARCH}$ \\
\hline \multirow{4}{*}{ Currency $^{a}$} & British Pound & 0.9520 & 0.9690 & & \\
\hline & Canadian Dollar & 0.8750 & 0.8910 & & \\
\hline & Japanese Yen & 0.9910 & 0.9990 & & \\
\hline & Swiss Franc & 0.9740 & 0.9760 & & \\
\hline \multirow{4}{*}{ Stock Index } & $S \& P 500^{b}$ & 0.9473 & 0.9558 & 0.9481 & 0.9526 \\
\hline & $\mathrm{NIKKEI}{ }^{\mathrm{C}}$ & 0.7993 & 0.8297 & & \\
\hline & FTSE $100^{c}$ & 0.7495 & 0.8015 & & \\
\hline & All ordinaries ${ }^{d}$ & 0.6740 & 0.7290 & & 0.7920 \\
\hline \multirow{4}{*}{ Agriculture } & Beef $^{e}$ & 0.0700 & & 0.9800 & \\
\hline & Corn ${ }^{e}$ & 0.6100 & & & \\
\hline & Wheat $^{f}$ & 0.9600 & & & \\
\hline & Canola $^{f}$ & 0.5800 & & 0.9200 & \\
\hline Fixed-Income & T-Bond (U.S.) ${ }^{g}$ & & & 0.4400 & \\
\hline \multirow{2}{*}{ Power } & Electricity $^{\mathrm{h}}$ & 0.2833 & & & \\
\hline & Crude Oil & 0.9900 & & & \\
\hline Metal & Gold $^{e}$ & 0.5000 & & & \\
\hline Emission & Carbon & 0.9143 & 0.9403 & & 0.9548 \\
\hline
\end{tabular}

It can be observed that all ratios lie within the range of 0.5 to 1 with the exception of some of the GARCH conditional hedge ratios - an OLS hedge ratio for beef. In Baillie \& Myers (1991), the hedge ratio for beef was found to have zero variance reduction, which in other words is not recommended for hedging application. This was later confirmed in Yang \& Awokuse (2003), where the hedge ratio for live cattle did not produce much variance reduction compared to no hedge at all. Hedge ratios for carbon emissions are listed last in the table. Despite its special features, the size of carbon hedge ratios is not so different from the other markets. 


\section{Conclusion}

This paper has investigated a number of approaches towards the estimation of the optimal hedge ratios in the EU-ETS carbon market, including Naïve, OLS, ECM, VECM and VECM-GARCH. Significant reduction of volatility can be attained if spot positions are hedged in futures market independent of the hedge ratio estimation method that is applied. However, the performance of models was not uniform. For example, the findings from this paper do not favour the use of the VECM-GARCH model for the hedging of EUA price risk. If the emitter chooses the minimum variance as the objective, the hedge ratio calculated by OLS estimation should be selected as it provides the greatest variance reduction compared to other models. However, if the hedger (not limited to emitters) expects to incorporate the return as well as minimum variance, a choice between OLS, Naive and ECM can be made. As suggested by the findings of this research, the results in terms of utility improvement are quite mixed in different hedging horizons. Nevertheless, the use of VECM-GARCH is also not recommended as it produces the lowest level of utility improvement overall. Comparing values of hedge ratios with hedge ratios obtained in other markets, no significant differences were found. Thus, in spite of the uniqueness and novelty of carbon markets, the estimated hedge ratios also fall in the range of 0.5 to 1 in line with those of other markets. 
However, due to various limitations of this study, future research is encouraged to further assess the performance of these models in the EU-ETS market environment. There are a number of issues which need to be considered - for example, the availability of phase II spot and futures data have restricted the analysis and testing. Once more data becomes available, a more accurate estimation will be forthcoming. The structural break in phase I of the EU-ETS is not represented in modeling and testing of this paper. To incorporate this, other studies have used dummy variables to represent such phenomenon. Again, these issues have not been studied in terms of hedging, therefore, further research is recommended. Ultimately, from the portfolio manager's perspective, the asset allocation problem and portfolio optimization can be revised after incorporating carbon instruments. Thus, management of risk and return on such revised portfolio becomes essential for possible future research. 


\section{References}

Ahmed, S. (2007). Effectiveness of time-varying hedge ratio with constant conditional correlation: an empirical evidence from the US treasury market. ICFAI Journal of Derivatives Markets 4: 22-30.

Alberola, E., Chevallier, J \& Cheze, B. (2008). Price drivers and structural breaks in European carbon prices 2005-2007. Energy Policy 36(2): 787-797.

Baillie, R. T., \& Myers, R. J. (1991). Bivariate GARCH estimation of the optimal commodity futures hedge. Journal of Applied Econometrics 6(2): 109-124.

Benz, E. \& Truck, S. (2009). Modeling the price dynamics of CO2 emission allowances. Energy Economics 31(1): 4-15

Bonacina, M., \& Cozialpi, S. (2009). Carbon allowance as inputs or financial assets: lesson learned from the pilot phase of the EU-ETS. IEFE Working Paper No.19. IEFE Università Bocconi.

Bystrom, H. N. E. (2003). The hedging performance of electricity futures on the Nordic power exchange. Applied Economics 35(1): 1-11.

Cetin, U., \& Verschuere, M. (2009). Pricing and hedging in carbon emissions markets. International. Journal of Theoretical and Applied Finance 12(7): 949-967.

Chevallier, J. (2008). The European carbon market (Phase I), banking pricing and risk hedging strategies. Unpublished Thesis (Ph.D.). Department of Economics, University of Paris. 
Copeland L. \& Zhu Y. (2006). Hedging effectiveness in the index futures market. Cardiff Business School Working Paper E2006/10, Cardiff University, Cardiff Business School, Economics Section.

Directive 2003/87/EC, (2003). Directive 2003/87/EC of the European Parliament and of the Council of October 2003 establishing a scheme for greenhouse gas emission allowance trading within the Community and amending Council Directive 96/61/EC. Official Journal of the European Union, L275, $32-46$.

Ederington, L.H. (1979). The hedging performances of the new futures markets. Journal of Finance 34(1): 157-170.

Ghosh, A., \& Clayton, R. (1996). Hedging with international stock index futures: an intertemporal error correction model. Journal of Financial Research 19(4): 477-492.

Hatemi-J, A., \& Roca, E. (2006). Calculating the optimal hedge ratio: constant, time varying and the Kalman Filter approach. Applied Economics Letters 13(5), 293 - 299.

Hintermann, B. (2009). Allowance price drivers in the first phase of the EU-ETS. CEPE Working Paper No. 63. Centre for Energy Policy and Economics, Swiss Federal Institutes of Technology.

Johnson, L. L. (1960). The theory of hedging and speculation in commodity futures. Review of Economic Studies 27(3): 139-151. 
Kenourgios, D., Samitas, A., \& Drosos, P. (2008). Hedge ratio estimation and hedging effectiveness: the case of the S\&P 500 stock index futures contract. International Journal of Risk Assessment and Management 9(1/2): 121-138.

Kroner, K. F., \& Sultan, J. (1993). Time-varying distributions and dynamic hedging with foreign currency futures. Journal of Financial and Quantitative Analysis 28(4): 535-551.

Lien, D. (2007). Statistical properties of post-sample hedging effectiveness. International Review of Financial Analysis 16(3): 293-300.

Lien, D., Tse Y. K. \& Tsui A. K. C. (2002). Evaluating the hedging performance of the constant correlation GARCH model. Applied Financial Economics 12(11): 791-798.

Mansanet-Bataller, M., Pardo, A., \& Valor, E. (2007). CO2 prices, energy and weather. The Energy Journal 28(3): 73-92

Moosa, I. (2003). The sensitivity of the optimal hedge ratio to model specification. Finance Letters 1(1): 15-20.

Myers, R. J., \& Thompson, S. R. (1989). Generalized optimal hedge ratio estimation. American Journal of Agricultural Economics 71(4): 858-868.

Rickels, W., Duscha, V., Keller, A., \& Peterson, S. (2007). The determinants of allowance prices in the European Emissions Trading Scheme - can we expect an efficient allowance market 2008. Kiel Working Papers No.1387. 
Kiel Institute for the World Economy.

Ripple, R. \& Moosa, I. (2007). Hedging effectiveness and futures contract maturity: the case of NYMEX crude oil futures. Applied Financial Economics, 17(9): 683-689.

Seifert, J., Uhrig-Homburg, M., \& Wagner, M. (2008). Dynamic behavior of CO2 spot prices. Journal of Environmental Economics and Management 56(2): 180-194

Sephton, P. S. (1993). Hedging wheat and canola at the Winnipeg Commodity Exchange. Applied Financial Economics 3(1): 67-72.

Uhrig-Homburg, M. \& Wagner, M. (2008). Derivative Instruments in the EU Emissions Trading Scheme - An Early Market Perspective. Energy \& Environment 19(5): 635-655

Yang, J. \& Awokuse, T. (2003). Asset storability and hedging effectiveness in commodity futures markets. Applied Economics Letters 10(8): 487-491.

Yang, J. W., \& Allen, D. E. (2004). Multivariate GARCH hedge ratios and hedging effectiveness in Australian futures markets. Accounting and Finance 45(2): $301-321$. 